\title{
Avaliação da rotulagem de leite UHT "zero lactose" comercializado na cidade de Natal/RN
}

\author{
Evaluation of UHT milk labeling "zero lactose" marketed in \\ the city of Natal/RN
}

Tatiane Leonel de Lima', Maria Andreza Borges de Macêdo', Renata Alexandra Moreira das Neves

'Universidade Federal do Rio Grande do Norte

E-mail para contato: Tatiane Leonel de Lima - tatileolima@hotmail.com

\section{Resumo}

O objetivo do presente estudo foi avaliar as conformidades das rotulagens geral e nutricional de leites UHT "zero lactose" de diferentes marcas comercializados em supermercados e hipermercados da cidade de Natal/RN, de acordo com os requisitos obrigatórios estabelecidos pelas normas técnicas brasileiras. A avaliação foi realizada através da aplicação de um Checklist com 42 recomendações especificadas pelas normas brasileiras vigentes sobre rotulagem de alimentos, incluindo as normas referentes a produtos de origem animal, devido ao tipo de amostra analisada. Foram avaliados os rótulos de 12 amostras de leite UHT Zero Lactose, sendo eles 4 integrais, 7 semi-desnatados e 1 desnatado. Todos os rótulos avaliados apresentaram alguma não conformidade com as normas brasileiras, no entanto, as amostras C, D, J, K e L foram as que apresentaram o maior número de não conformidades, com um percentual de $60,8 \%$ do total das irregularidades. Conclui-se que, apesar dos órgãos reguladores estabelecerem regras e normas para a rotulagem de alimentos, ainda assim, são identificados o não cumprimento de muitas das exigências estabelecidas pelas legislações vigentes.

Palavras-chave: Rotulagem de alimentos. Laticínios. Intolerância à Lactose. Legislação.

\begin{abstract}
The objective of the present study was to evaluate the conformity of the general and nutritional labeling of UHT "zero lactose" milks of different brands marketed in supermarkets and hypermarkets in the city of Natal / RN, according to the mandatory requirements established by Brazilian technical standards. The evaluation was carried out through the application of a Check list with 42 recommendations specified by the current Brazilian rules on food labeling, including the rules regarding products of animal origin, due to the type of sample analyzed. Were evaluated the labels of 72 samples of UHT Zero Lactose milk, being 4 whole, 7 semi-skimmed and 7 skimmed. All labels evaluated showed some noncompliance with Brazilian standards, however, samples C, D, J, K and L were the ones with the highest number of non-conformities, with a percentage of $60,8 \%$ of total irregularities. It was concluded that, although the regulatory agencies establish rules and norms for the labeling of foods, nonetheless, the non-fulfillment of many of the requirements established by the current legislation is identified.
\end{abstract}

Keywords: Food labeling. Dairy products. Lactose intolerance. Legislation. 


\section{INTRODUÇÃO}

O leite, sem outra especificação, é o produto oriundo da ordenha completa e ininterrupta, em condições de higiene, de vacas sadias, bem alimentadas e descansadas ${ }^{1}$. É considerado um alimento de grande importância na alimentação humana, devido ao seu alto valor nutritivo, apresentando quantidades consideráveis de proteína, gordura, vitaminas, sais minerais e carboidratos, principalmente a lactose ${ }^{2}$.

A lactose é um dissacarídeo constituído por glicose e galactose, que atua no fornecimento de energia e no favorecimento da absorção de cálcio, fósforo e magnésio, mas para que ocorra a absorção, é necessária sua degradação através da atividade da enzima $\beta$-galactosidase (lactase). Porém, muitos indivíduos possuem déficit total ou parcial na produção desta enzima, acarretando sintomas gastrointestinais como náusea, diarreia, flatulência e dores abdominais, sendo considerados como intolerantes a lactose. Apesar disso, não é recomendada a exclusão de alimentos que possuem a lactose na sua constituição química, como o leite e seus derivados, da dieta, pois pode acarretar prejuízos nutricionais, e consequentemente, danos à saúde ${ }^{3,4}$.

Baseando-se neste contexto, a indústria láctea vem inovando com a oferta de produtos com teor reduzido ou isento de lactose, entre eles o leite Ultra High Temperature (UHT) zero lactose. Na produção do leite UHT zero lactose, a hidrólise da lactose se dá por meio enzimático, em que a enzima $\beta$-galactosidase é adicionada ao produto após o processamento térmico de ultrapasteurização, promovendo a hidrólise da lactose. Este método é amplamente utilizado para leite UHT, e, embora promova algumas alterações físico-químicas e sensoriais no produto, como favorecimento da reação de Maillard e doçura excessiva pelo aumento do teor de glicose, o produto continua oferecendo um alto valor nutritivo, assim como o produto original ${ }^{5,6}$.

A Portaria No 146 de 07 de março de 1996, regulamenta a identidade e qualidade do leite UHT e define o mesmo como o leite homogeneizado que foi submetido, durante 2 a 4 segundos, a uma temperatura de $130^{\circ} \mathrm{C}$, mediante um processo térmico de fluxo contínuo, imediatamente resfriado a uma temperatura inferior a $32^{\circ} \mathrm{C}$ e envasado sob condições assépticas em embalagens estéreis e hermeticamente fechadas. 
Com o intuito de garantir a qualidade e a segurança dos alimentos ofertados para a população, como o leite UHT, são estabelecidos pela legislação brasileira, parâmetros de identidade e requisitos mínimos de qualidade para os alimentos industrializados $^{8}$. As informações contidas na rotulagem dos alimentos devem ser bem claras, de modo que não causem danos à saúde do consumidor e confusão no momento da leitura desta, devendo ser fidedignas, além de atenderem as normas estabelecidas pelas legislações vigentes.

Levando-se em consideração esses aspectos, objetivou-se avaliar as conformidades das rotulagens geral e nutricional de leites UHT "zero lactose" de diferentes marcas comercializados em supermercados e hipermercados da cidade de Natal/RN, de acordo com os requisitos obrigatórios estabelecidos pelas normas técnicas brasileiras.

\section{MÉTODO}

\section{Amostra}

Foram avaliados 12 rótulos de 9 marcas diferentes de leites UHT zero lactose classificados de acordo com 0 teor de gordura, comercializados em 5 estabelecimentos (mercados, supermercados e hipermercados) localizados em 4 bairros da cidade de Natal, Rio Grande do Norte (RN), Brasil, entre os meses de fevereiro a agosto de 2018. E, com intuito de preservar a identidade dos fabricantes, as amostras foram codificadas aleatoriamente pelas letras A, B, C, D, E, F, G, H, I, J, $\mathrm{K}$ e L, como pode ser visualizado na tabela 1.

Como critérios de inclusão, foram analisados os rótulos dos leites UHT na sua forma integral, semi-desnatado e desnatado que declaravam ausência de lactose, de fabricantes com registro no Serviço de Inspeção Federal (SIF), órgão responsável pela inspeção de produtos de origem animal.

Tabela 1 - Marcas de Leite UHT Zero Lactose disponíveis no comércio local de Natal/RN, Brasil, 2018.

\begin{tabular}{c|c|c|c}
\hline \multicolumn{2}{c}{ Amostra } & \multicolumn{3}{c}{ Leite UHT Zero Lactose } \\
\hline A & Integral & Semi-desnatado & Desnatado \\
B & - & 1 & - \\
C & - & 1 & - \\
D & - & 1 & - \\
E & 1 & - & - \\
F & - & 1 & - \\
\hline
\end{tabular}




\begin{tabular}{c|c|c|c}
\hline \multicolumn{2}{c}{ Amostra } & \multicolumn{3}{c}{ Leite UHT Zero Lactose } \\
\hline G & Integral & Semi-desnatado & Desnatado \\
H & - & 1 & - \\
I & 1 & - & - \\
J & 1 & - & - \\
K & - & - & - \\
L & 1 & - & 1 \\
\hline Total & - & $\mathbf{7}$ & $\mathbf{1}$ \\
\hline
\end{tabular}

- Ausência.

\section{Coleta de dados}

A coleta dos dados foi realizada por observação direta, no próprio local de venda, utilizando como instrumento de coleta um checklist, elaborado conforme às normas brasileiras vigentes sobre rotulagem de alimentos, incluindo as normas referentes a produtos de origem animal, devido ao tipo de amostra analisada. A rotulagem geral foi avaliada de acordo com a RDC No 259/2002 (ANVISA) ${ }^{9}$, Portarias $\mathrm{N}^{\mathrm{o}}$ 29/1998(SVS/MS) ${ }^{10}$ e $\mathrm{N}^{\mathrm{o}}$ 157/2002 (INMETRO) ${ }^{11}$, Instrução Normativa (IN) $\mathrm{N}^{0} 22 / 2005$ (MAPA) ${ }^{12}$ e pelo decreto $\mathrm{N}^{\mathrm{0}} 6.523 / 2008^{13}$ e Artigo 467 do decreto $\mathrm{N}^{\mathrm{o}}$ 9.013/2017 $7^{14}$. E a rotulagem nutricional foi verificada conforme as RDCs $\mathrm{N}^{0} 359^{15}$, $\mathrm{N}^{0} 360 / 2003^{16}$ e $\mathrm{N}^{0} 135 / 2017$ (ANVISA) ${ }^{17}$.

O checklist foi organizado com 42 recomendações especificadas para rotulagem do leite UHT, distribuídas em 12 grupos, 9 correspondentes a rotulagem geral e 3 a rotulagem nutricional do leite $U H T$, sendo eles, respectivamente: Identificação do estabelecimento produtor; nomenclatura oficial do produto; conteúdo líquido; conservação do produto; data de fabricação, prazo de validade e lote; identificação de registro no serviço oficial de inspeção; dizeres, informações e imagens não permitidas; ortografia, unidade de medida e tamanho da letra; frase obrigatória estabelecida para alimentos para lactentes e crianças de primeira infância; informação nutricional; lista de ingredientes e informações nutricionais de alimentos para dietas com restrição de lactose. Após a avaliação de cada rótulo, os itens foram classificados em conforme (C), não conforme (NC) e não se aplica (NA). O Quadro 1 representa o modelo de checklist utilizado para verificação dos rótulos. 
Quadro 1 - Modelo de check list aplicado para verificação das conformidades da rotulagem de leite UHT, sem lactose, comercializado na cidade de Natal/RN, Brasil, 2018

\begin{tabular}{|c|c|c|c|c|}
\hline \multicolumn{5}{|c|}{ IDENTIFICAÇÃO DO ESTABELECIMENTO PRODUTOR } \\
\hline Recomendações & C & NC & NA & Legislação correspondente \\
\hline 1.Razão Social ou nome, completo & & & & \multirow{5}{*}{ IN N²2 / 2005 (MAPA) } \\
\hline 2. Endereço completo & & & & \\
\hline 3.CNPJ ou CPF & & & & \\
\hline $\begin{array}{l}\text { 4.Informações do importador, caso o produto seja } \\
\text { importado }\end{array}$ & & & & \\
\hline 5.Marca comercial & & & & \\
\hline 6.Expressões "fabricado em...", "produto... ou "indústria..." & & & & RDC N $259 / 2002$ (ANVISA) \\
\hline 7.Número de telefone para contato ou SAC & & & & BRASIL / Decreto Nº6.523) / 2008 \\
\hline \multicolumn{5}{|c|}{ NOMENCLATURA OFICIAL DO PRODUTO } \\
\hline Recomendações & C & NC & NA & Legislação correspondente \\
\hline 8.Denominação de venda/nome verdadeiro do produto & & & & \multirow{4}{*}{ IN N 22 / 2005 (MAPA) } \\
\hline 9.Localização do nome do produto no painel principal & & & & \\
\hline $\begin{array}{l}\text { 10.Nome em caracteres destacados, igual a maior fonte do } \\
\text { rótulo }\end{array}$ & & & & \\
\hline $\begin{array}{l}\text { 11. Nome em caixa alta e negrito, uniforme e sem } \\
\text { intercalação }\end{array}$ & & & & \\
\hline \multicolumn{5}{|c|}{ CONTEÚDO LÍQUIDO } \\
\hline Recomendações & C & NC & NA & Legislação correspondente \\
\hline $\begin{array}{l}\text { 12.Indicação do conteúdo localizada no painel principal } \\
\text { (fácil visualização) }\end{array}$ & & & & \multirow{2}{*}{ Portaria N¹57 / 2002 (INMETRO) } \\
\hline $\begin{array}{l}\text { 13.Tamanho dos caracteres de acordo com o volume ou } \\
\text { área do rótulo }\end{array}$ & & & & \\
\hline
\end{tabular}

Os dados coletados foram tabulados no programa Microsoft Excel ${ }^{\circledR}$ (2013). Com o emprego da análise estatística descritiva, foi possível verificar as conformidades e não conformidades de cada produto frente à legislação.

\section{RESULTADOS}

Com base nos resultados obtidos no presente estudo, foi possível observar que, todas as marcas avaliadas apresentaram alguma não conformidade com as recomendações das legislações vigentes para rotulagem geral e nutricional do leite UHT. A Figura 1 demonstra o percentual de não conformidades de cada amostra avaliada.

Figura 1 - Percentual de não conformidades na rotulagem de cada uma das 12 amostras de leite UHT zero lactose (denominadas de A a L), comercializados na cidade de Natal/RN, Brasil, 2018.

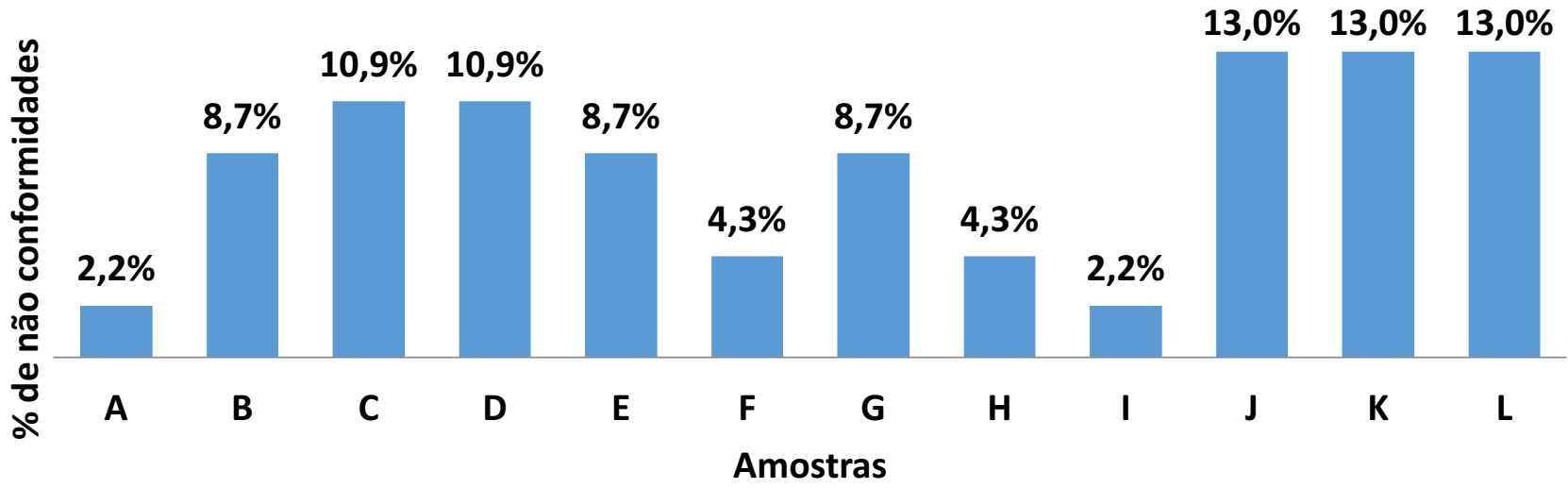


A Tabela 2 revela o quantitativo de amostras que apresentaram alguma irregularidade de acordo com os grupos de recomendações do checklist. Ao avaliar a rotulagem das amostras conforme o conjunto de recomendações distribuídas em 12 categorias foi verificado que as principais não conformidades estavam relacionadas aos grupos: Nomenclatura oficial do produto (oito amostras); Dizeres, informações e imagens não permitidas (sete amostras); Informação nutricional (sete amostras); Frase obrigatória estabelecida p/ alimentos p/ lactentes e crianças de primeira infância (seis amostras); Ortografia, unidade de medida e tamanho da letra (cinco amostras), respectivamente.

É notório que, nos grupos "Identificação de registro no serviço oficial de inspeção" e "Lista de ingredientes" todas as amostras atenderam as recomendações estabelecidas pela legislação vigente, como pode ser observado na Tabela 2.

Tabela 2 - Número total de não conformidades por grupo avaliado no checklist, encontradas nas diferentes marcas de leite UHT sem lactose comercializada em Natal/RN, Brasil, 2018.

\begin{tabular}{|c|c|c|c|c|c|c|c|c|c|c|c|c|c|}
\hline \multirow[b]{2}{*}{ Grupos avaliados } & \multicolumn{12}{|c|}{ Amostras de Leite UHT Zero Lactose } & \multirow{2}{*}{$\begin{array}{c}\text { Total de } \\
\text { amostras } \\
\text { NC }\end{array}$} \\
\hline & A & B & C & D & $\mathbf{E}$ & $\mathbf{F}$ & G & $\mathbf{H}$ & $\mathbf{I}$ & J & $\mathbf{K}$ & $\mathbf{L}$ & \\
\hline $\begin{array}{l}\text { Nomenclatura oficial do } \\
\text { produto }\end{array}$ & $\mathrm{C}$ & NC & NC & NC & NC & NC & $\mathrm{C}$ & $\mathrm{C}$ & $\mathrm{C}$ & NC & NC & NC & 8 \\
\hline $\begin{array}{l}\text { Dizeres, informações e } \\
\text { imagens não permitidas }\end{array}$ & NC & C & C & NC & NC & C & C & C & NC & NC & NC & NC & 7 \\
\hline Informação nutricional & C & C & NC & NC & C & NC & C & NC & C & NC & NC & NC & 7 \\
\hline $\begin{array}{l}\text { Frase obrigatória estabelecida } \\
\mathrm{p} / \text { alimentos p/ lactentes e } \\
\text { crianças de primeira infância }\end{array}$ & C & NC & C & NC & C & C & C & NC & C & NC & NC & NC & 6 \\
\hline $\begin{array}{l}\text { Ortografia, unidade de } \\
\text { medida e tamanho da letra }\end{array}$ & C & NC & NC & C & C & C & $C$ & C & C & NC & NC & NC & 5 \\
\hline Conteúdo líquido & C & C & C & NC & C & C & C & C & C & C & $C$ & NC & 2 \\
\hline Conservação do produto & C & C & C & C & NC & C & NC & C & C & C & C & C & 2 \\
\hline $\begin{array}{l}\text { Data de fabricação, prazo de } \\
\text { validade e lote }\end{array}$ & C & C & C & C & $C$ & C & NC & C & C & C & C & C & 1 \\
\hline $\begin{array}{l}\text { Identificação do } \\
\text { estabelecimento produtor }\end{array}$ & C & C & C & C & C & C & NC & C & C & C & C & C & 1 \\
\hline $\begin{array}{l}\text { Informações nutricionais de } \\
\text { alimentos para dietas com } \\
\text { restrição de lactose }\end{array}$ & C & C & NC & C & C & C & C & C & C & C & C & $C$ & 1 \\
\hline Lista de ingredientes & C & C & C & $C$ & C & C & C & $C$ & C & C & C & C & 0 \\
\hline $\begin{array}{l}\text { Identificação de registro no } \\
\text { serviço oficial de inspeção }\end{array}$ & C & C & C & C & C & C & C & C & C & C & C & C & 0 \\
\hline
\end{tabular}

C - Conforme; NC - Não conforme.

O Quadro 2 apresenta quais recomendações encontram-se irregulares em cada amostra avaliada. É importante destacar que, as amostras podem apresentar mais de uma não conformidade em um mesmo grupo de recomendações. 
Quadro 2 - Não conformidades encontradas nos rótulos de leite UHT zero lactose comercializado em Natal/RN, Brasil, 2018.

\begin{tabular}{|c|c|}
\hline AMOSTRAS & NÃO CONFORMIDADES \\
\hline $\mathbf{A}$ & Destacava a presença de componentes intrínsecos ao produto. \\
\hline B & $\begin{array}{l}\text { Nome oficial do produto sem negrito e com pouco destaque/informação obrigatória com caracteres } \\
\text { de tamanho, realce e visibilidade inadequados/Frase estabelecida ara lactentes e criança de primeira } \\
\text { infância exibida com pouca visibilidade. }\end{array}$ \\
\hline C & $\begin{array}{l}\text { Nome oficial do produto sem negrito e com pouco destaque/informação obrigatória com caracteres } \\
\text { de tamanho, realce e visibilidade inadequados/Apresentava medida caseira equivalente a } 100 \mathrm{~mL} \text { a } \\
\text { legislação estabelece } 200 \mathrm{~mL} \text { para leite fluído/ Não declarava os monossacarídeos (glicose e galactose) } \\
\text { na tabela nutricional. }\end{array}$ \\
\hline D & $\begin{array}{l}\text { Nome oficial do produto com pouco visibilidade/Indicação do conteúdo líquido com pouca visualização } \\
\text { no painel principal/Destacava a presença de componentes intrínsecos ao produto/Frase estabelecida } \\
\text { para lactentes e criança de primeira infância exibida com pouca visibilidade/Apresentava medida } \\
\text { caseira equivalente a } 100 \mathrm{~mL} \text {, a legislação estabelece } 200 \mathrm{~mL} \text { para leite fluído. }\end{array}$ \\
\hline E & $\begin{array}{l}\text { Nome oficial do produto sem negrito/Não informava as temperaturas máxima e mínima de } \\
\text { conservação após abertura/Trazia informação que induz ao erro e confusão sobre características do } \\
\text { produto. }\end{array}$ \\
\hline $\mathbf{F}$ & $\begin{array}{l}\text { Nome oficial do produto sem negrito /Apresentava medida caseira equivalente a } 100 \mathrm{~mL} \text {,a legislação } \\
\text { estabelece } 200 \mathrm{~mL} \text { para leite fluído. }\end{array}$ \\
\hline $\mathbf{G}$ & $\begin{array}{l}\text { Não apresenta o número do SAC/Não informa as temperaturas máxima e mínima de conservação após } \\
\text { abertura /Não apresentava o número do lote. }\end{array}$ \\
\hline $\mathbf{H}$ & $\begin{array}{l}\text { Frase estabelecida para lactentes e criança de primeira infância exibida com pouca } \\
\text { visibilidade/Apresentava medida caseira equivalente a } 100 \mathrm{~mL} \text {, a legislação estabelece } 200 \mathrm{~mL} \text { para } \\
\text { leite fluído. }\end{array}$ \\
\hline $\mathbf{I}$ & Destacava a presença de componentes intrínsecos ao produto \\
\hline J & $\begin{array}{l}\text { Nome oficial do produto com pouco destaque em caracteres/Trazia informação que induz ao erro e } \\
\text { confusão sobre características do produto/Destacava a presença de componentes intrínsecos ao } \\
\text { produto/Frase estabelecida para lactentes e criança de primeira infância exibida com pouca } \\
\text { visibilidade/Apresentava medida Caseira equivalente a } 100 \mathrm{~mL} \text {, a legislação estabelece } 200 \mathrm{~mL} \text { para } \\
\text { leite fluído. }\end{array}$ \\
\hline $\mathbf{K}$ & $\begin{array}{l}\text { Nome oficial do produto com pouco destaque em caracteres/Trazia informação que induz ao erro e } \\
\text { confusão sobre características do produto/Destacava a presença de componentes intrínsecos ao } \\
\text { produto/ Informação obrigatória com pouca visibilidade/ Frase estabelecida para lactentes e criança } \\
\text { de primeira infância exibida com pouca visibilidade/Apresentava medida caseira equivalente a } 100 \mathrm{~mL} \text {, } \\
\text { a legislação estabelece } 200 \mathrm{~mL} \text { para leite fluído. }\end{array}$ \\
\hline $\mathbf{L}$ & $\begin{array}{l}\text { Nome oficial do produto sem negrito/Indicação do conteúdo líquido com pouca visualização no painel } \\
\text { principal/ Destacava a presença de componentes intrínsecos ao produto/Informação obrigatória com } \\
\text { pouca visibilidade/Frase estabelecida para lactentes e criança de primeira infância exibida com pouca } \\
\text { visibilidade/Apresentava medida caseira equivalente a } 100 \mathrm{~mL} \text {, a legislação estabelece } 200 \mathrm{~mL} \text { para } \\
\text { leite fluído. }\end{array}$ \\
\hline
\end{tabular}

\section{DISCUSSÃO}

De acordo com a FAO/OMS a rotulagem de alimentos é considerada uma ferramenta para proteção da saúde do consumidor em termos de segurança alimentar e de promoção do bem-estar nutricional. À medida que as evidências científicas que relacionam a dieta e saúde se expandem e se aprofundam, existe a necessidade de fornecer mais informações nutricionais para os consumidores. Um dos principais motivos para utilização da rotulagem nutricional é o aumento da prevalência de doenças não transmissíveis relacionados à dieta ${ }^{18}$.

As legislações que regulamentam a rotulagem são desenvolvidas para impedir fraudes e informações enganosas e, além disso, para que sejam um meio de comunicação entre o consumidor e o produto, assegurando o direito ao acesso a toda informação que diz respeito ao alimento, e que estas sejam claras e garantam a 
compreensão dos consumidores, permitindo a busca por uma alimentação saudável ${ }^{19}$.

Neste aspecto, observou-se no presente estudo que, as amostras avaliadas não cumprem completamente as exigências das legislações vigentes para rotulagem geral e nutricional, considerando que, todas as amostras apresentaram pelo menos uma irregularidade em sua rotulagem.

Resultados semelhantes foram encontrados por Torquato, Occhioni, Sousa e Miyoshi et al. que, ao analisarem a rotulagem de diferentes amostras de leites UHT (integral, semidesnatado e desnatado) comercializados no município do Rio de Janeiro (RJ) e Curitiba, respectivamente, verificaram uma alta taxa de não conformidades com a legislação. Ressalta-se que quanto maior a quantidade de itens analisados nos estudos, maior a possibilidade de haver irregularidades ${ }^{20,21}$.

Na tabela 2 é possível identificar que oito amostras apresentaram não conformidades no grupo "Nomenclatura oficial do produto", onde a denominação de venda do produto estava sem negrito e os caracteres apresentava-se sem destaque (Quadro 2). Essas falhas podem ser consideradas mínimas, porém repercutem diretamente na diminuição da legibilidade da nomenclatura do produto, e conforme o regulamento técnico para produtos de origem animal, a IN $\mathrm{N}^{0} 22 / 2005$, o nome do produto de origem animal deve ser indicado no painel principal do rótulo em caracteres destacados, uniformes em corpo e cor, sem intercalação de desenhos e outros dizeres, em caixa alta e em negrito ${ }^{12}$.

As amostras A, D, E, I, J, K, L apresentaram não conformidades dentro da categoria "Dizeres, informações e imagens não permitidas", destacando a presença de componentes que foram adicionados e/ou a presença de componentes intrínsecos ao produto (Quadro 2), como "Rico em vitaminas A, C e D" e "Fonte de Cálcio e Proteínas". Mesmo o cálcio sendo essencial para o crescimento e a manutenção do nosso organismo, em especial para as crianças que estão em fase de desenvolvimento, a informação da presença destes nutrientes pode influenciar a compra, bem como favorecer a marca diante de produtos similares, utilizando-se de supervalorização $0^{21,22}$.

Além disso, as amostras A, D, E, I, J, K, L trazem informações que podem induzir a confusão sobre o consumo do produto, como "Você e sua família podem consumir normalmente [...]", induzindo as pessoas que não possuem intolerância à lactose a serem também consumidores desse produto. Entretanto, segundo a Sociedade 
Brasileira de Alimentação e Nutrição (SBAN), não há evidência científica suficiente para que indivíduos saudáveis retirem a lactose da dieta ${ }^{23}$. Além dessas alegações, foram encontradas frases que favorecem a compra do produto, pois destacam que o mesmo é o único que possui qualidade superior, possivelmente, por não apresentar conservantes na lista de ingredientes. Essa informação precisa ser confirmada pela autoridade sanitária local.

Com base nas recomendações do grupo "informação nutricional", as amostras C, D, $\mathrm{F}, \mathrm{H}, \mathrm{J}, \mathrm{K}, \mathrm{L}$ não atenderam ao que rege a legislação quanto às informações nutricionais obrigatórias, apresentando na tabela nutricional a porção de $100 \mathrm{~mL}$ e não a de $200 \mathrm{~mL}$ (Quadro 2). A RDC nº 359/2003, regulamento técnico de porções de alimentos embalados para fins de rotulagem nutricional, estabelece, para leite fluído, a porção de $200 \mathrm{~mL}$, equivalente a um copo ${ }^{15}$. Conforme Camara e Weschenfelder "a informação da porção na rotulagem nutricional é pertinente, para que o consumidor tenha conhecimento sobre a quantidade média do alimento que poderá ser consumida e neste sentido poder controlar e monitorar a sua ingestão calórica, bem como de nutrientes" 22 .

Os dados do presente estudo (Tabela 2) também apontam que, as amostras B, D, H, $\mathrm{J}, \mathrm{K}, \mathrm{L}$ em relação à frase obrigatória estabelecida para alimentos para lactentes e crianças de primeira infância, que trata-se especificamente dessa informação: "AVISO IMPORTANTE: Este produto somente deve ser usado na alimentação de crianças menores de 1 (um) ano de idade com indicação expressa de médico ou nutricionista. $O$ aleitamento materno evita infecções e alergias e fortalece o vínculo mãe-filho" mostrouse pouco visível e muito embaixo do painel principal das embalagens (Quadro 2). Esta informação foi instituída pela Lei $\mathrm{N}^{\mathrm{o}} 11.265$ de 3 de janeiro de 2006, alterada pela Lei $\mathrm{N}^{\mathrm{o}}$ 11.474, de 15 de maio de 2007. E cabe destacar a relevância dessa informação para a saúde da clientela a que se destina essa recomendação, considerando a importância do aleitamento materno ${ }^{24}$.

Não conformidades relacionadas à ortografia, unidade de medida e tamanho da letra (Tabela 2) foram identificadas em 5 amostras (B, C, J, K, L). As informações obrigatórias como a denominação de venda do produto, identificação do estabelecimento produtor, letras e números da tabela nutricional, enunciado sobre a conservação do produto e lista de ingredientes apresentaram pouca visibilidade quanto ao tamanho da letra e cor utilizada na descrição (Quadro 2). Essas informações não atendem a RDC No 259/2002, a qual estabelece que o tamanho das 
letras e números da rotulagem obrigatória não pode ser inferior a $1 \mathrm{~mm}$ e que a informação obrigatória deve estar com caracteres de tamanho, realce e visibilidade adequados, constatando que os fabricantes seguem o limite recomendado pela legislação9 .

Os dados referentes às análises dos rótulos quanto ao conteúdo líquido (Tabela 2), indicam que duas amostras ( $\mathrm{D}$ e L) apresentaram irregularidades como a indicação do conteúdo líquido com pouca visualização, e muito embaixo do painel principal (Quadro 2), contrariando o que é determinado na Portaria $\mathrm{N}^{0} 157 / 2002$, que estabelece a forma de expressar o conteúdo líquido a ser utilizado nos produtos prémedidos ${ }^{11}$.

As informações obrigatórias e o conteúdo líquido são fundamentais para o consumidor conhecer as características do produto que está adquirindo e auxiliar na escolha deste conforme a sua necessidade, e caso os critérios estabelecidos pela legislação não sejam seguidos, pode interferir na escolha do produto pelo consumidor e até ocasionar falsas expectativas ${ }^{21}$.

Na embalagem das amostras E e G (Tabela 2), não constava a temperatura de conservação após abertura da embalagem, apenas o prazo de validade após a abertura foi descrito, como apresenta o Quadro 2. Essa informação deve estar presente, de acordo com a Instrução Normativa $N^{0} 22 / 2005$, na qual estabelece no subitem 6.6.2 que "nos rótulos das embalagens de produto de origem animal devem ser indicadas as temperaturas máxima e mínima para a conservação do produto e o tempo que o fabricante, produtor ou fracionador garante sua durabilidade nessas condições" ${ }^{\prime 2}$. As instruções sobre a conservação do produto são importantes para que o consumidor saiba como realizar o armazenamento antes e após a sua abertura, indicando as precauções necessárias para manter suas características preservadas, bem como manter a qualidade do produto para que este, se mal armazenado, não venha ocasionar danos à saúde do consumidor ${ }^{20}$.

Com relação à data de fabricação, prazo de validade e lote, apenas a amostra G (Tabela 2) apresentou não conformidade, pois em seu rótulo não havia a presença do número do lote (Quadro 2), sendo este um dos itens obrigatórios estabelecido pela RDC N²59/2002 e pela IN No 22/2005, de suma importância para o controle da produção do leite ou de qualquer alimento, contribuindo para o rastreamento do mesmo. Ambos os regulamentos determinam que todo rótulo deve ter impresso, gravado ou marcado de qualquer outro modo, uma indicação em código ou 
linguagem clara, que permita identificar o lote a que pertence o produto de origem animal, de forma que seja visível, legível e indelével ${ }^{9,12}$. Como sugerem Camara e Weshenfelder, caso a identificação do lote não fosse um critério obrigatório, seria basicamente impossível ter acesso aos produtos com necessidade de recolhimento, por exemplo, e assim, as indústrias teriam problemas com o controle de sua produção ${ }^{22}$.

Nesse estudo, com relação ao item "identificação do estabelecimento produtor" todas as amostras apresentaram conformidades para os setes itens avaliados, com exceção da amostra G (que não apresentava o número do Serviço de Atendimento ao Consumidor (SAC), sendo um item estabelecido pelo decreto $\mathrm{N}^{\mathrm{0}} 6.523$, de 31 de julho de 2008, que tem como finalidade resolver as demandas dos consumidores sobre informação, dúvida, reclamação, suspensão ou cancelamento de contratos e de serviços $^{13}$. Diferente do estudo de Camara e Weschenfelder que identificou $100 \%$ de conformidade nos dados referentes à denominação de venda nos rótulos de leite UHT integral ${ }^{22}$.

A amostra C não declara em sua tabela de informação nutricional (Quadro 2), os monossacarídeos glicose e galactose. Este parâmetro é regulamentado pela RDC No 135/2017, que dispõe sobre os alimentos para dietas com restrição de lactose. Nessa resolução foi estabelecido um prazo de 24 meses a partir da sua publicação, para os produtores se adequarem as exigências estabelecidas. Portanto, os fabricantes do Leite UHT zero lactose deverão em breve atualizar essas informações ${ }^{17}$. De acordo com Oliveira, Feitosa e Almeida, a informação nutricional, além de informar o quantitativo dos nutrientes, surge como uma forma de facilitar a escolha do produto, principalmente por indivíduos que possuem intolerância à algum constituinte nocivo a saúde ou até mesmo uma dieta estabelecida, em que é necessário controlar a quantidade de ingestão do componente ${ }^{25}$. Torquato, Occhioni, Sousa também relatam que o consumidor ao ler as informações nutricionais, tem a possibilidade de optar por alimentos mais saudáveis, contribuindo assim para uma alimentação balanceada $^{20}$.

Todas às amostras apresentaram conformidade com dois parâmetros utilizados para avaliação da rotulagem (Tabela 2), "Identificação de registro no serviço oficial de inspeção" e "Lista de ingredientes", diferentemente do estudo de Silva et al. que, ao avaliar a rotulagem geral e nutricional de 6 amostras de leite UHT zero lactose identificaram que, uma das amostras estava não conforme com relação a lista de 
ingredientes, pois a enzima lactase do rótulo, estava em último lugar, indicando que era o ingrediente em menor proporção, porém, os estabilizantes é que são os ingredientes em menor proporção no leite ${ }^{26}$.

De acordo com Sousa, a respeito da rotulagem, estudos têm demonstrado deficiências nas informações de rótulos de alimentos no que se referem à composição química, valores nutricionais, denominação de origem, acessibilidade a serviços de atendimento ao consumidor, ausência de rótulo em alimentos clandestinos, falta do número de registro e uso de mensagens confusas que podem levar o consumidor a erros ou riscos à saúde ${ }^{27}$.

\section{CONCLUSÃO}

Foi visto que todas as amostras apresentaram alguma não conformidade, permitindo afirmar que as legislações referentes à rotulagem de alimentos, em especial ao leite UHT zero lactose, não estão sendo criteriosamente seguidas. Todos os itens exigidos pelas legislações que tratam sobre rotulagem de alimentos são de fundamental importância. A rotulagem pode viabilizar a escolha de um determinado alimento pelo consumidor, seja no momento da compra ou posterior consumo, sendo considerada uma importante ferramenta na educação nutricional, bem como na contribuição para escolhas alimentares mais saudáveis.

\section{REFERÊNCIAS}

1. Ministério da Agricultura, Pecuária e Abastecimento (MAPA). Instrução Normativa $\mathrm{N}^{\circ}$ 62, de 29 de dezembro de 2011. Aprova o Regulamento Técnico de Produção, Identidade e Qualidade do Leite tipo A, o Regulamento Técnico de Identidade e Qualidade de Leite Cru Refrigerado, o Regulamento Técnico de Identidade e Qualidade de Leite Pasteurizado e o Regulamento Técnico da Coleta de Leite Cru Refrigerado e seu Transporte a Granel, em conformidade com os Anexos desta Instrução Normativa. Diário Oficial da União. 2011 dez 30; (Seção1).

2. Beloti V. Leite: Obtenção, Inspeção e Qualidade. 1a ed. Londrina: Planta; 2015.414 p.

3. Koga E C. Desenvolvimento e avaliação de leite em pó com baixo teor de lactose obtido por liofilização [Dissertação Mestrado na internet]. Londrina: Universidade Norte do Paraná; 2015 [Acesso 2018 jan 27]. 62 p. Disponível em: http://repositorio.pgsskroton.com.br/bitstream/123456789/721/1/DESENVOLVI MENTO\%20E\%20AVALIA\%C3\%87\%C3\%83O\%20DE\%2OLEITE\%20EM\%20P\% C3\%93\%20COM.pdf

4. Faedo R, Barbosa Brião V, CastoldiS , Girardelli L, Milani A. Obtenção de leite com baixo teor de lactose por processos de separação por membranas associados à hidrólise enzimática. Rev CIATEC [Internet]. 2013 [Acesso 2008 jan 28]; 3(1):44- 
54. Disponível em:

http://www.seer.upf.br/index.php/ciatec/article/viewFile/3222/2386.

5. Ministério da agricultura, do abastecimento, e da reforma agrária. Portaria $\mathrm{N}^{0} 146$, de 07 de março de 1996. Aprova os Regulamentos Técnicos de Identidade e Qualidade dos Produtos Lácteos em anexo. Diário Oficial da União. 1996 mar 11; (Seção 1).

6. Weschenfelder S. Elaboração e avaliação físico-química e microbiológica de produtos lácteos obtidos a base de Kefir [Tese Doutorado na internet]. Porto Alegre: Universidade Federal do Rio Grande do Sul; 2016 [Acesso 2018 jan 28]. 114 p. Disponível em:

http://www.lume.ufrgs.br/bitstream/handle/10183/142254/000993383.pdf?sequ ence $=1$.

7. Agência nacional de Vigilância Sanitária (ANVISA). Resolução RDC No 259, de 20 de setembro de 2002. Aprova regulamento técnico sobre rotulagem de alimentos embalados. Diário Oficial da União. 2002 set 23; (Seção 1):33.

8. Ministério da Saúde. Secretaria de Vigilância Sanitária. Portaria $\mathrm{N}^{0} 29$, de 13 de janeiro de 1998. Aprova o regulamento técnico referente a alimentos para fins especiais. Diário oficial da união. 1998 jan 15 1998; (Seção 1).

9. Instituto Nacional de Metrologia, Normalização e Qualidade Industrial (INMETRO). Portaria $\mathrm{N}^{\mathrm{O}}$ 157, de 19 de agosto de 2002. Aprova o Regulamento Técnico Metrológico estabelecendo a forma de expressar o conteúdo líquido a ser utilizado nos produtos pré-medidos[Internet]. 2002 [Acesso 2018 jun 15]. Disponível em: http://www.inmetro.gov.br/legislacao/rtac/pdf/RTAC000786.pdf.

10. Ministério da Agricultura, Pecuária e do Abastecimento (MAPA). Instrução normativa $\mathrm{N}^{0} 22$, de 24 de novembro de 2005. Aprova o regulamento técnico sobre rotulagem de produto de origem animal embalado. Diário Oficial da União. 2005 nov 25; (Seção 1):1.

11. Presidência da República. Casa Civil. Decreto No 6.523, de 31 de julho de 2008. Regulamenta a Lei no 8.078/90, de 11 de setembro de 1990, para fixar normas gerais sobre o Serviço de Atendimento ao Consumidor (SAC) [Internet]. 2008 [Acesso 2018 jan 24]. Disponível em:

http://www.planalto.gov.br/ccivil_03/_at020072010/2008/decreto/d6523.htm.

12. Presidência da República. Secretaria Geral. Decreto No 9.013, de 29 de março de 2017. Regulamenta a Lei $n^{0} 1.283$, de 18 de dezembro de 1950 , e a Lei $n^{0} 7.889$, de 23 de novembro de 1989, que dispõem sobre a inspeção industrial e sanitária de produtos de origem animal. [Internet]. Diário Oficial da União. 2017 mar 30 [Acesso 2018 jun 15]; (Seção 1):3. Disponível em:

http://www.planalto.gov.br/ccivil_03/_at02015-2018/2017/decreto/d9013.htm.

13. Agência Nacional de Vigilância Sanitária (ANVISA). Resolução RDC No 359, de 23 de dezembro 2003. Aprova o Regulamento Técnico de Porções de Alimentos Embalados para Fins de Rotulagem Nutricional, conforme o Anexo. Diário Oficial da União. 2003 dez 26; (Seção 1):28.

14. Agência nacional de Vigilância Sanitária (ANVISA). Resolução RDC No 360, de 23 de dezembro de 2003. Aprova o regulamento técnico sobre rotulagem nutricional de alimentos embalados. Diário Oficial da União. 2003 dez 26; (Seção 1). 
15. Agência Nacional de vigilância sanitária (ANVISA). Resolução RDC No 135 , de 8 de fevereiro de 2017. Altera a Portaria SVS/MS N²29, de 13 de janeiro de 1998, que aprova o regulamento técnico referente a alimentos para fins especiais, para dispor sobre os alimentos para dietas com restrição de lactose. Diário oficial da união. 2017 fev 9; (Seção 1):44.

16. Torquato VSA, Occhioni CVO, Sousa MRP. Avaliação da rotulagem de leites UAT comercializados por estabelecimentos varejistas no município do Rio de Janeiro - RJ, Brasil. Vet. Not. 2018;22(2):19-23.

17. Miyoshi LY, Galvão JA, Weber LFS, Mantovani SL, Junior PIT, Raldi T. Rotulagem de leites UHT comercializados no varejo. Rev. Inst. Lat Cândido Tostes. 2016; 71(1):19-25.

18. Camara F A, Weschenfelder S. Leite UHT integral: Avaliação da rotulagem nutricional e dos padrões de identidade e qualidade. Rev. Inst. Lat Cândido Tostes.2014; 69(4):268-279.

19. Agência Nacional de vigilância sanitária (ANVISA). Lei $n^{0} 11.474$, de 15 de maio de 2007. Altera a $n^{0} 10.188$, de 12 de fevereiro de 2001, que cria o programa de Arrendamento Residencial, institui o arrendamento residencial com opção de compra, e a lei $n^{0} 11.265$, de 3 de janeiro de 2006, regulamenta a comercialização de alimentos para lactentes e crianças de primeira infância e também a de produtos de puericultura correlatos. Diário Oficial da União. 2007 mai 16. [Acesso 2018 jun 17]; (Seção 1): 1. 2007 mai 16. Disponível em:

http://www.planalto.gov.br/ccivil_03/_ato2007-2010/lei/l11474.htm

20. Silva THB, Lima FL, Fernandes, APS, Soares DSP, Pinto EG. Avaliação da rotulagem do leite UHT zero lactose. Hig Alim [Internet]. 2019 [Acesso 2020 nov 12]; 33(288/289):2903-2907. Disponível em:

https://higienealimentar.com.br/wp-content/uploads/2020/08/AnaisHigienistas-2019 VERS\%C3\%830-ATUALIZADA-FINAL compressed.pdf

21. Sousa JR. Avaliação da rotulagem e dos teores de gordura de leite e produtos lácteos inspecionados nos Programas de Vigilância Sanitária. Rev. Inst. Adolfo Lutz. 2014; 73(1): 87-95.

22. Ranciaro A, Campbell MC, Hirbo JB, Ko WE, Froment A, Anagnostou P, et al. Genetic origins of lactase persistence and the spread of pastoralism in Africa. The American Journal of Human Genetics [Internet]. 2014 [Acesso 2020 nov 27]; 94(4):496-510. Disponível em: https://www.ncbi.nlm.nih.gov/pmc/articles/PMC3980415/

23. Food and Agriculture Organization. Milk and dairy products in human nutrition [Internet]. Rome: 2013. [Acesso 2020 nov 27]. 404 p. Disponível em: www.fao.org/docrep/018/i3396e/i3396e.pdf

24. Santos GJ, Rocha R, Santana GO. Lactose intolerance: what is a correct management? Rev. Assoc. Med. Bras. [Internet] 2019 [Acesso 2020 nov 28]; 65(2):270-275. Disponível em: http://www.scielo.br/scielo.php?script=sci_arttext\&pid=S010442302019000200270\&Ing=en.

25. Dantas A, Verruck S, Prudencio ES. Ciência e Tecnologia de leite e produtos Lácteos Sem Lactose [E-book na Internet]. Ponta Grossa/PR: Atena Editora, 2019. [Acesso 2020 nov 30]. 74p. Disponível em:https://www.atenaeditora.com.br/arquivos/ebooks/ciencia-e-tecnologiade-leite-e-produtos-lacteos-sem-lactose 
26. Food and Agriculture Organization of the United Nations. Handbook on food labeling to protect consumers [Internet]. Rome: 2016. [Acesso 2020 nov 27]. 60 p. Disponível em: http://www.fao.org/documents/card/en/c/fc5f4bc2-650a4704-9162-9eb9b3aifddo/

27. Morais WS, Silva Filho CRM. Análise da rotulagem de leites UHT comercializados na cidade de Campina Grande estado da Paraíba, Brasil. Rev. Educ. Cont. Med. Vet. Zootec. [Internet]. 2016 [Acesso 2020 dez 1];14(3):65-65. Disponível em: https://www.revistamvezcrmvsp.com.br/index.php/recmvz/article/view/34802

28. Sociedade Brasileira de Alimentação e Nutrição. Declaração de Posicionamento da Sociedade Brasileira de Alimentação e Nutrição sobre Consumo de Leite e de Produtos Lácteos e Intolerância à Lactose [Internet]. São Paulo, 2017. [Acesso 2020 jun 15]. 15p. Disponível em: http://www.sban.org.br/posicionamentos.aspx

29. Oliveira ENA, Feitosa BF, Almeida FLC. Avaliação das informações nutricionais e distribuições obrigatórias presentes na rotulagem de leites UHT. In: Congresso Nacional da Diversidade do Semiárido [Internet]; 2018 Dez 12-14; Campina Grande: Realize Editora;2018 [Acesso 2020 dez 1]. Disponível em: https://editorarealize.com.br/artigo/visualizar/50566.

Submissão: $16 / 11 / 2020$

Aprovação: 18/12/2020 